\title{
Medical Students' and Residents' preferred site characteristics and preceptor behaviours for learning in the ambulatory setting: a cross-sectional survey
}

\author{
Karen W Schultz*1, John Kirby ${ }^{2}$, Dianne Delva ${ }^{1}$, Marshall Godwin ${ }^{1}$, \\ Sarita Verma ${ }^{1}$, Richard Birtwhistle ${ }^{1}$, Chris Knapper ${ }^{3}$ and Rachelle Seguin ${ }^{1}$
}

Address: ${ }^{1}$ Department of Family Medicine, Queen's University, 220 Bagot St., PO Bag 8888, Kingston, ON, Canada, K7L 5E9, ${ }^{2}$ Faculty of Education, Queen's University, 511 Union St., Kingston, ON, Canada, K7M 5R4 and ${ }^{3}$ Department of Psychology, Queen's University Kingston, ON, Canada, K7L 3N6

Email: Karen W Schultz* - kws@post.queensu.ca; John Kirby - kirbyj@educ.queensu.ca; Dianne Delva - mdd2@post.queensu.ca; Marshall Godwin - godwinm@post.queensu.ca; Sarita Verma - sv3@post.queensu.ca; Richard Birtwhistle - birtwhis@post.queensu.ca; Chris Knapper - knapper@psyc.queensu.ca; Rachelle Seguin - seguinr@post.queensu.ca

* Corresponding author

Published: 06 August 2004

BMC Medical Education 2004, 4:12 doi:10.1 186/1472-6920-4-12
Received: 08 December 2003

Accepted: 06 August 2004

This article is available from: http://www.biomedcentral.com/1472-6920/4/12

(C) 2004 Schultz et al; licensee BioMed Central Ltd.

This is an open-access article distributed under the terms of the Creative Commons Attribution License (http://creativecommons.org/licenses/by/2.0), which permits unrestricted use, distribution, and reproduction in any medium, provided the original work is properly cited.

\begin{abstract}
Background: Medical training is increasingly occurring in the ambulatory setting for final year medical students and residents. This study looks to identify if gender, school, level of training, or speciality affects learner's (final year medical students and residents) preferred site characteristics and preceptor behaviours for learning in the ambulatory setting.

Methods: All final year medical students and residents at the five medical schools in Ontario ( $N=$ 347I) were surveyed about the site characteristics and preceptor behaviours most enhancing their learning in the ambulatory setting. Preferred site characteristics and preceptor behaviours were rank ordered. Factor analysis grouped the site characteristics and preceptor behaviours into themes which were then correlated with gender, school, level of training, and speciality.

Results: Having an adequate number and variety of patients while being supervised by enthusiastic preceptors who give feedback and are willing to discuss their reasoning processes and delegate responsibility are site characteristics and preceptor behaviours valued by almost all learners. Some teaching strategies recently suggested to improve efficiency in the ambulatory teaching setting, such as structuring the interview for the student and teaching and reviewing the case in front of the patient, were found not to be valued by learners. There was a striking degree of similarity in what was valued by all learners but there were also some educationally significant differences, particularly between learners at different levels and in different specialities. Key findings between the different levels include preceptor interaction being most important for medical students as opposed to residents who most value issues pertaining to patient logistics. Learning resources are less valued early and late in training. Teaching and having the case reviewed in front of the patient becomes increasingly less valued as learners advance in their training. As one approaches the end of ones' training office management instruction becomes increasingly valued. Differences between specialities pertain most to the type of practice residents will ultimately end up in (ie: office based specialties particularly valuing instruction in office management and health care system interaction).
\end{abstract}




\begin{abstract}
Conclusions: Preceptors need to be aware of, and make efforts to provide, teaching strategies such as feedback and discussing clinical reasoning, that learners have identified as being helpful for learning. If strategies identified as not being valued for learning, such as teaching in front of the patient, must continue it will be important to explore the barriers they present to learning. Although what all learners want from their preceptors and clinic settings to enhance their learning is remarkably similar, being aware of the educationally significant differences, particularly for learners at different levels and in different specialities, will enhance teaching in the ambulatory setting.
\end{abstract}

\section{Background}

"The ideal preceptor should be like Captain Picard from Star Trek, who has a good grasp of situations but lets his subordinates push themselves to their limits without interfering/imposing his views and methods"! (survey comment)

Medical care is being delivered primarily in the ambulatory setting in an increasing number of specialties. Since learning is best done contextually $[1,2]$ it is appropriate and necessary that medical training also increasingly occur in the ambulatory setting. Theory suggests that trainees at different levels [3-8] and in different specialties [3,6,9-11] may have different learning needs. Students early in their training may be looking to be taught certainties about facts and concepts, corresponding to Perry's concept of simple dualism, ie; right versus wrong, and to not find it helpful to be engaged in discussions about "softer" emotional and social issues [5]. Stritter found first year residents preferred being told what to do, whereas higher-level residents preferred more autonomy and more explanations from their preceptors [7]. Work looking at learning styles in different specialities has been mainly based on Kolb's work, who outlined four different learning styles, and suggests those in different specialities learn differently (ie: surgeons learn best by hands-on practical application of ideas [11], while pathologists learn best using abstract theoretical models [10]).

An article by Kernan [12] outlined site accommodations and preceptor behaviours that third year medical students felt facilitated their learning during a one-month ambulatory internal medicine rotation. A pilot project at our institution asking first year family medicine residents to rank Kernan's study items found differences between the two groups. What was not clear was if these differences were due to school attended, level of training or specialty. Given that trainees at all levels and in all specialties are increasingly being trained in the ambulatory setting, it seemed important to understand if there truly are differences between different types of students in what is perceived as being most helpful for learning. If differences are identified it will then be important to study whether adjusting to these differences actually improves learning.
We surveyed all final year medical students and residents in Ontario about the site characteristics and preceptor behaviours that they find most enhance learning in the ambulatory setting and determined if these were related to demographic factors, level of training or residency program. Implications for teaching in the ambulatory setting are explored based on these results.

\section{Methods}

All medical students $(n=532)$ and residents $(n=2939)$ at the five medical schools in Ontario were surveyed using a four part questionnaire which collected information on demographics, preferred site characteristics, preferred preceptor behaviours, and approaches to learning and perceptions of learning climate. Questions for the site characteristics and preceptor behaviours included previously validated questions [12-15] and questions believed to be important by study group consensus. The approaches to learning and perceptions of learning climate questionnaire was validated by Kirby et al [16] and is not reported here.

Students rated 24 site characteristics and 38 preceptor behaviours on a Likert scale from 1 (very important for learning) to 5 (not at all important for learning) or D (detrimental for learning). Within each section they indicated the five most important and 5 most unimportant or detrimental items for learning. A section for general comments was included at the end of the survey. The survey was piloted with a group of Queen's University residents and final year medical students checking for ambiguity and content. Ethical approval was granted by the Queen's University General Research Ethics Board. To ensure privacy for their students schools requested that the questionnaires be addressed by their own undergraduate and postgraduate offices. Coded questionnaires were thus sent with student's names and bulk mailed to the undergraduate and postgraduate medical schools who then addressed and forwarded the questionnaires to their final year medical students and residents. Entry into a draw for a Personal Digital Assistant or equivalent monetary prize was offered for completed surveys. Non-responders were identified by a lack of a returned coded questionnaire. Two subsequent mailings were sent to the non-respondents 
through their schools' undergraduate or postgraduate office. In addition an email reminder was sent to everyone between the second and third mailing.

Data were analyzed using SPSS for Windows, version 11.0 [17]. A systematic effort to look for out-of-range data was conducted by doing frequency distributions for each of the variables, identifying out-of-range entries and correcting the errors by going back to the original data sheets. Double entry data assessment was not done. Frequency distributions for demographic factors, valued site characteristics, and preceptor behaviours were compiled. Counts were derived for each site characteristic or preceptor behaviour by calculating percentages of respondents giving the item a score of 1 or 2 on the Likert scale. Detrimental items were tallied from the frequency data. Factor analysis of the site characteristics and preceptor behaviours was carried out. Cronbach alpha coefficients were calculated for the identified factors. (Factor analysis is a means of reducing a large number of items to a smaller, more manageable number of dimensions, based on the ways in which the items correlate with each other. Cronbach alpha coefficients can then be calculated for internal consistency of the scales based on the identified factors. The resulting factors/scales need to be interpreted, but may provide a view of underlying constructs that are responsible for the observed variables and their correlations. Both the choice of the number of factors to extract and the interpretation of the factors/scales are matters of interpretation [18].) Counts (derived by calculating percentages for each item ranked 1 or 2 on the Likert scale) were generated for gender, school, level of training and residency for each factor. The Post-Graduate Year 2 (PGY2) group had an additional, possibly confounding feature, containing a large number of family medicine residents, who would be at the end of their training, instead of half way through their training like the remainder of the group. A subanalysis was done on the level of training data removing family medicine residents from the PGY2 data to analyse the impact of this on preferred site characteristics and preceptor behaviours. Initial data interpretation for residency used 11 residencies. Residencies were then collapsed into five groups (medicine; family medicine, paediatrics, psychiatry; lab/path, radiology; surgery, emergency, ob/gyn; and intensivists, anaesthetists) based on similarity of practice patterns. Logistic regression analysis[17] was used to compare gender, school, level of training and residency with respect to the site characteristic and preceptor behaviour factors. Each independent variable (ie: gender, school, level of training and residency grouping) was entered individually into a regression procedure as a categorical variable and the proportion of positive responses ( 1 or 2 on the Likert scale) for each level of the variable was compared to the proportion of positive responses in the full sample.

\section{Results}

Survey response was 48\% (1642/3430). Of these 44 had not worked in an ambulatory setting and so were eliminated from further analysis $(\mathrm{N}=1598)$. The demographics of the five medical schools are listed in Table 1 . Demographic characteristics of responders are shown in Table 2. Comparisons to all Ontario and Canadian clerks and residents revealed more women, junior residents, McMaster and Family Medicine residents and fewer PGY6fellows and Toronto trainees responded.

The rank ordering of site characteristics and preceptor behaviours, including missing data and number judging an item to not only be unhelpful but detrimental for learning are shown in Tables 3 and 4. The five most and five least important items for learning essentially matched the rank ordering and thus are not separately reported.

Six factors, accounting for $55 \%$ of the variance for the 24 site characteristics, and 7 factors, accounting for $54 \%$ of the variance for the 38 preceptor behaviours, were identified (Tables 5,6). Labels describing the factors were decided by group consensus among the researchers. 7 items that failed to load on any factor were eliminated from the analysis. The site characteristic factors were office management, patient logistics, objectives, learning resources, clinic set-up and preceptor interaction. The preceptor behaviour factors were professional role modeling, teaching, learning climate, feedback, direction, patient presence and health care system interaction. Cronbach alpha coefficients for the factors identified in the factor analysis ranged from 0.52 to 0.83 .

Table I: Demographics of the five medical schools

\begin{tabular}{llcc}
\hline \multicolumn{1}{c}{ School } & City Size & $\begin{array}{c}\text { \# final year medical students } \\
(\mathbf{2 0 0} \text { I-02)* }\end{array}$ & \# residents (200 I-02)* \\
\hline Queen's University & 113,000 & 71 & 248 \\
University of Toronto & $4,700,000$ & 167 & 1268 \\
University of Western Ontario & 432,000 & 98 & 353 \\
University of Ottawa & 823,000 & 85 & 398 \\
McMaster University & 662,000 & 103 & 396
\end{tabular}

* Data from Association of Canadian Medical Colleges 
Table 2: Demographics of Study Group

\begin{tabular}{|c|c|}
\hline Demographic & Study Numbers N (\%) \\
\hline Gender & $N=1642$ \\
\hline Male & $805(49)$ \\
\hline Female & $837(51)$ \\
\hline Level of Training & $N=|64|$ \\
\hline Clerks & $279(17.0)$ \\
\hline First year residents & $377(23.0)$ \\
\hline Second year residents & $366(22.3)$ \\
\hline Third year residents & $23 \mid(\mid 4.1)$ \\
\hline Fourth year residents & $165(10.1)$ \\
\hline Fifth year residents & $185(11.3)$ \\
\hline Sixth and above year residents including Fellows & $38(2.3)$ \\
\hline University & $N=1642$ \\
\hline Queen's U. & $172(10.5)$ \\
\hline U. of Toronto & $611(37.3)$ \\
\hline U. of Western Ontario & $243(14.8)$ \\
\hline Ottawa U. & $296(18.0)$ \\
\hline McMaster U. & $317(19.3)$ \\
\hline Mean Age Residents & 29.9 \\
\hline Training Program & $N=1356 * * *$ \\
\hline Medicine & $298(22.0)$ \\
\hline Family Medicine & $351(25.9)$ \\
\hline Paediatrics & $100(7.4)$ \\
\hline Surgery & $226(16.7)$ \\
\hline Psychiatry & $104(7.7)$ \\
\hline Radiology & $56(4.1)$ \\
\hline Intensivists & $7(0.5)$ \\
\hline Anaesthesia & $102(7.5)$ \\
\hline Laboratory & $24(1.8)$ \\
\hline Obstetrics/Gynaecology & $65(4.8)$ \\
\hline Emergency & $23(1.7)$ \\
\hline
\end{tabular}

$* N=$ total number-clerks $* * 7$ not specified

Logistic regression analysis of the independent variables revealed striking similarities, but some significant differences, in valued site characteristics and preceptor behaviours for male and female students and those in different schools, at different levels of training and in different residencies (Figures 1,2,3,4,5,6,7,8). Similarities are evident by mainly flat, nonintersecting lines on the graphs indicating similar percentages of subgroups of learners valuing a factor and similar relative valuing of factors respectively. Differences are apparent where lines intersect within a graph and/or percentages are statistically higher (indicated by $*, * *, * * *)$ or lower $(\#, \# \#, \# \#)$ than the means.

Male and female residents rank ordered all site characteristics and preceptor behaviours identically. Women ranked all factors, with the exception of teaching in the patient's presence, higher than men, usually significantly so (Figures 1,2).

Across schools the rank ordering of factors was identical with the exception of Toronto and Ottawa ranking office management instruction higher than the other schools. Toronto valued six factors significantly more than the other schools, Queen's and Western ranked three and two items respectively significantly less than the other schools (Figures 3,4).

Across levels the only difference in rank ordering was clerks ranking preceptor interaction as the most important site characteristic whereas all other groups ranked patient logistics as most important. Those at the beginning and end of their training valued having learning resources available less than all other levels. Clerks were most different from all the other levels in what they valued or did not value (indicated by the number of * and \# for this group) (Figures 5,6). Subanalysis of the PGY2 data removing family medicine residents significantly decreased the importance of office management and health care system interaction instruction $52.2 \%$ of all PGY2's rated office management instruction important versus $44.8 \%$ removing family medicine residents, and $60.1 \%$ of all PGY2's rated health care system interaction instruction important versus $50.5 \%$ removing family medicine residents). Resi- 
Table 3: Ranking of Site Characteristics

\begin{tabular}{|c|c|c|c|c|}
\hline Rank & Question & $\begin{array}{l}\text { Number saying } \\
\text { important to learning } \\
\text { (\%) }\end{array}$ & $\begin{array}{l}\text { Number not answering } \\
\text { question }\end{array}$ & $\begin{array}{l}\text { Number saying } \\
\text { detrimental for } \\
\text { learning (\%) }\end{array}$ \\
\hline I & Effective teachers & $1569(98.4)$ & 4 & $3(0.2)$ \\
\hline 2 & Opportunity to see patients independently & $1592(97.3)$ & 6 & 0 \\
\hline 3 & Opportunity to see a large variety of patients & $151 \mid(94.8)$ & 4 & $\mathrm{I}(0.1)$ \\
\hline 4 & $\begin{array}{l}\text { Opportunity to see an adequate number of } \\
\text { patients }\end{array}$ & 1496 (93.9) & 5 & $2(0.1)$ \\
\hline 5 & Preceptors readily available & $1490(93.5)$ & 4 & $2(0.1)$ \\
\hline 6 & Opportunity to do procedures & $1357(85.3)$ & 8 & $3(0.2)$ \\
\hline 7 & Readily available examination room & I $348(84.8)$ & 9 & $\mathrm{I}(0.1)$ \\
\hline 8 & Opportunity to see patients in follow-up visits & $1275(80.1)$ & 6 & $I(0.1)$ \\
\hline 9 & Opportunity to observe preceptor if desired & $1239(77.8)$ & 6 & 0 \\
\hline 10 & $\begin{array}{l}\text { Opportunity to interact with consultants and/ } \\
\text { or referring doctors }\end{array}$ & $1227(77.1)$ & 7 & 0 \\
\hline II & Block rotation & $1094(68.8)$ & 7 & $3(0.2)$ \\
\hline 12 & Efforts to meet objectives made by preceptor & $1059(66.5)$ & 5 & $I(0.1)$ \\
\hline 13 & Teaching of medical record keeping skills & $956(60.0)$ & 4 & 0 \\
\hline 14 & $\begin{array}{l}\text { Computer learning resources available in the } \\
\text { clinic }\end{array}$ & $947(59.4)$ & 3 & 0 \\
\hline 15 & Orientation to the practice & $937(59.0)$ & 11 & $\mathrm{I}(0 . \mathrm{l})$ \\
\hline 16 & Teaching of time management skills & $904(56.7)$ & 3 & $3(0.2)$ \\
\hline 17 & Teaching of office management skills & $872(54.7)$ & 4 & $2(0.1)$ \\
\hline 18 & $\begin{array}{l}\text { Clearly defined site objectives for the } \\
\text { rotation }\end{array}$ & $843(52.9)$ & 5 & $4(0.2)$ \\
\hline 19 & Library resources available in the clinic & $778(48.8)$ & 4 & 0 \\
\hline 20 & Existence of a site-coordinator & $762(48.4)$ & 22 & $2(0.1)$ \\
\hline 21 & Longitudinal/horizontal rotation & $603(38.4)$ & 29 & $42(2.7)$ \\
\hline 22 & Limited number of preceptors & $443(27.9)$ & 13 & $233(14.7)$ \\
\hline 23 & Presence of other trainees in the clinic & $432(27.1)$ & 4 & $74(4.6)$ \\
\hline 24 & Close proximity of clinic to campus & $366(23.0)$ & 8 & $5(0.3)$ \\
\hline
\end{tabular}

Table 4: Preceptor Behaviours Ranking

\begin{tabular}{|c|c|c|c|c|}
\hline Rank & Question & $\begin{array}{l}\text { Number saying } \\
\text { important for learning } \\
\text { (\%) }\end{array}$ & $\begin{array}{l}\text { Number not answering } \\
\text { question }\end{array}$ & $\begin{array}{l}\text { Number saying } \\
\text { detrimental for } \\
\text { learning (\%) }\end{array}$ \\
\hline I & Is open to questions & $1540(96.7)$ & 5 & $\mathrm{I}(0.1)$ \\
\hline 2 & Gives constructive feedback & $1522(95.6)$ & 6 & $\mathrm{I}(0.1)$ \\
\hline 3 & Demonstrates enthusiasm for teaching & $1515(95.1)$ & 5 & $\mathrm{I}(0.1)$ \\
\hline 4 & Reviews differential diagnoses & $1507(94.6)$ & 5 & 0 \\
\hline 5 & $\begin{array}{l}\text { Delegates appropriate responsibility for } \\
\text { patient care }\end{array}$ & $149 \mid(93.7)$ & 7 & $\mathrm{I}(0.1)$ \\
\hline 6 & Gives timely feedback & $1445(90.7)$ & 5 & 0 \\
\hline 7 & Has a strong command of his or her specialty & $1433(90.1)$ & 7 & $2(0.1)$ \\
\hline 8 & Discusses clinical topics in an organized way & $1416(88.9)$ & 5 & 0 \\
\hline 9 & $\begin{array}{l}\text { Makes student feel like a valued member of } \\
\text { the practice }\end{array}$ & $1407(88.3)$ & 5 & $\mathrm{I}(0 . \mathrm{I})$ \\
\hline 10 & $\begin{array}{l}\text { Identifies and responds to student's specific } \\
\text { learning needs }\end{array}$ & $1398(87.9)$ & 8 & $\mathrm{I}(0.1)$ \\
\hline 11 & Discusses own clinical reasoning processes & $1396(87.3)$ & 8 & $\mathrm{I}(0.1)$ \\
\hline 12 & Asks for students' ideas before giving own & $1372(86.1)$ & 5 & 0 \\
\hline 13 & Discusses clinical topics concisely & $136 \mid(85.5)$ & 6 & $\mathrm{I}(0.1)$ \\
\hline 14 & $\begin{array}{l}\text { Demonstrates a caring attitude towards } \\
\text { students }\end{array}$ & $1347(84.6)$ & 5 & $\mathrm{I}(0.1)$ \\
\hline 15 & $\begin{array}{l}\text { Sets time aside to discuss topics unable to be } \\
\text { discussed during busy clinics }\end{array}$ & $1340(84.3)$ & 10 & $4(0.3)$ \\
\hline 16 & $\begin{array}{l}\text { Provides a role model of professional } \\
\text { behaviour }\end{array}$ & $1327(83.5)$ & 8 & 0 \\
\hline
\end{tabular}


Table 4: Preceptor Behaviours Ranking (Continued)

\begin{tabular}{|c|c|c|c|c|}
\hline 17 & $\begin{array}{l}\text { Asks students differing complexities of } \\
\text { questions }\end{array}$ & $1302(81.8)$ & 6 & $3(0.2)$ \\
\hline 18 & Welcomes differing points of view & $1294(81.3)$ & 7 & $2(0.1)$ \\
\hline 19 & $\begin{array}{l}\text { Demonstrates a caring attitude towards } \\
\text { patients }\end{array}$ & $1279(80.3)$ & 5 & 0 \\
\hline 20 & $\begin{array}{l}\text { Facilitates student's participation in follow-up } \\
\text { care }\end{array}$ & $1263(79.4)$ & 7 & 0 \\
\hline 21 & Teaches physical examination & $1218(76.8)$ & 13 & $3(0.2)$ \\
\hline 22 & Monitors quality of the rotation & $1216(76.4)$ & 6 & $I(0.1)$ \\
\hline 23 & Seeks to understand student's ideas & I I $86(74.5)$ & 6 & 0 \\
\hline 24 & Suggests relevant reading & $1172(73.6)$ & 5 & 0 \\
\hline 25 & Connects new ideas to existing knowledge & 1149 (72.4) & 10 & 0 \\
\hline 26 & Defines student's role & $1087(68.4)$ & 8 & $3(0.2)$ \\
\hline 27 & $\begin{array}{l}\text { Provides a role model of a balance between } \\
\text { personal and professional life }\end{array}$ & $1079(67.9)$ & 9 & 0 \\
\hline 28 & $\begin{array}{l}\text { Teaches appropriate use of health care } \\
\text { resources }\end{array}$ & $1072(67.4)$ & 8 & 0 \\
\hline 29 & Teaches use of community resources & $1005(63.2)$ & 7 & 0 \\
\hline 29 & $\begin{array}{l}\text { Demonstrates effective interactions with } \\
\text { support staff }\end{array}$ & $1005(63.2)$ & 9 & 0 \\
\hline 30 & Observes clinical interactions directly & $966(60.8)$ & 8 & $7(0.4)$ \\
\hline 31 & Teaches communication skills & $940(59.2)$ & 10 & $2(0.1)$ \\
\hline 32 & $\begin{array}{l}\text { Discusses limitations of his or her own } \\
\text { knowledge }\end{array}$ & $899(56.5)$ & 7 & $I(0.1)$ \\
\hline 33 & $\begin{array}{l}\text { Provides background on patients before } \\
\text { students sees patient }\end{array}$ & $602(37.8)$ & 5 & $36(2.3)$ \\
\hline 34 & $\begin{array}{l}\text { Outlines specific task(s) to be done during a } \\
\text { clinical encounter }\end{array}$ & $595(37.5)$ & 12 & $30(1.9)$ \\
\hline 35 & Teaches in the patient's presence & $429(27.1)$ & 14 & $116(7.3)$ \\
\hline 36 & Focuses on one teaching theme per clinic & $348(21.9)$ & 9 & $71(4.4)$ \\
\hline 37 & Reviews case in the patient's presence & $281(17.7)$ & 10 & $242(15.1)$ \\
\hline
\end{tabular}

Table 5: Factor Analysis makeup for Site Characteristics

\begin{tabular}{llll}
\hline Factor & Items making up factor & Factor Loading & Alpha Analysis \\
\hline Office Management & Teaching of time management skills & .832 & .62 \\
& Teaching of medical record keeping skills & .760 & .746 \\
Patient Logistics & Teaching of office management skills & .766 & .69 \\
& Opportunity to see an adequate number of patients & .542 & .538 \\
& Opportunity to see a large variety of patients & .473 & .542 \\
& Opportunity to see patients independently & .53 \\
Objectives & Readily available examination room & .806 & .60 \\
Learning Resources & Opportunity to see patients in follow-up visits & .776 \\
Clinic Set-up & Clearly defined site objectives for the rotation & .794 & .55 \\
& Efforts to meet objectives made by preceptor & .756 & .442 \\
& Library resources available in the clinic & .418 \\
& Computer learning resources available in the clinic & .386 \\
Preceptor Interaction & Close proximity of clinic to campus & .364 \\
& Presence of other trainees in the clinic & .342 \\
& Existence of a site co-coordinator & .514 \\
& Longitudinal/horizontal rotation & .506 \\
\end{tabular}


Table 6: Factor analysis for Preceptor Behaviours

\begin{tabular}{|c|c|c|c|}
\hline Factor & Items Making Up Factor & Factor Loading & Alpha Analysis \\
\hline \multirow[t]{6}{*}{ Professional Role Modeling } & Provides a role model of professional behaviour & .681 & .79 \\
\hline & Demonstrates effective interactions with support staff & .565 & \\
\hline & $\begin{array}{l}\text { Provides a role model of a balance between personal } \\
\text { and professional life }\end{array}$ & .557 & \\
\hline & Teaches communication skills & .526 & \\
\hline & Discusses limitations of his or her own knowledge & .500 & \\
\hline & Discusses own clinical reasoning processes & .426 & \\
\hline \multirow[t]{10}{*}{ Teaching } & Discusses clinical topics in an organized way & .739 & .82 \\
\hline & Discusses clinical topics concisely & .650 & \\
\hline & Suggests relevant reading & .462 & \\
\hline & $\begin{array}{l}\text { Identifies and responds to student's specific learning } \\
\text { needs }\end{array}$ & .390 & \\
\hline & Is open to questions & .365 & \\
\hline & Asks students differing complexities of questions & .362 & \\
\hline & Has a strong command of his or her area of specialty & .340 & \\
\hline & Asks for students' ideas before giving own & .334 & \\
\hline & $\begin{array}{l}\text { Sets time aside to discuss topics unable to be discussed } \\
\text { during busy clinics }\end{array}$ & .323 & \\
\hline & Monitors quality of the rotation & .301 & \\
\hline \multirow[t]{7}{*}{ Learning Climate } & $\begin{array}{l}\text { Makes student feel like a valued member of the } \\
\text { practice }\end{array}$ & .613 & .83 \\
\hline & Demonstrates a caring attitude towards students & .591 & \\
\hline & Seeks to understand student's ideas & .563 & \\
\hline & Demonstrates a caring attitude towards patients & .512 & \\
\hline & Demonstrates enthusiasm for teaching & .365 & \\
\hline & Welcomes differing points of view & .328 & \\
\hline & Facilitates student's participation in follow-up care & .301 & \\
\hline \multirow[t]{3}{*}{ Feedback } & Gives constructive feedback & .730 & .73 \\
\hline & Gives timely feedback & .709 & \\
\hline & Reviews differential diagnosis & .473 & \\
\hline \multirow[t]{5}{*}{ Direction } & $\begin{array}{l}\text { Outlines specific task(s) to be done during a clinical } \\
\text { encounter }\end{array}$ & .588 & .69 \\
\hline & Focuses on one teaching theme per clinic & .507 & \\
\hline & $\begin{array}{l}\text { Provides background on patients before student sees } \\
\text { patient }\end{array}$ & .447 & \\
\hline & Teaches physical examination & .432 & \\
\hline & Defines student's role & .404 & \\
\hline \multirow[t]{2}{*}{ Patient Presence } & Teaches in the patient's presence & .759 & .77 \\
\hline & Reviews case in the patient's presence & .720 & \\
\hline \multirow{2}{*}{$\begin{array}{l}\text { Health Care System } \\
\text { Interaction }\end{array}$} & Teaches use of community resources & .531 & .82 \\
\hline & Teaches appropriate use of health care resources & .516 & \\
\hline
\end{tabular}

dency groups again showed mainly similarities in rank ordering, the exceptions being the family medicine/paediatrics/psychiatry group ranking office management and learning climate higher, the lab/path/radiology group patient logistics and learning climate lower and the surgery/emergency/ob/gyn group health care system interaction lower than the rest. There were a large number of responses significantly different from the group averages throughout all the residency groups (Figures 7,8). Combining residencies into five groups lost only two pieces of information, that of ob/gyn residents being similar to the family medicine, paediatrics, psychiatry group in relatively highly valuing office management instruction and that of anaesthesia residents being similar to lab/path, radiology residents in relatively less valuing feedback, teaching, and learning climate than other groups.

\section{Discussion}

The ambulatory teaching site characteristics most valued by clerks and residents are having an adequate number and variety of patients while being supervised by enthusiastic and available preceptors. These characteristics have 


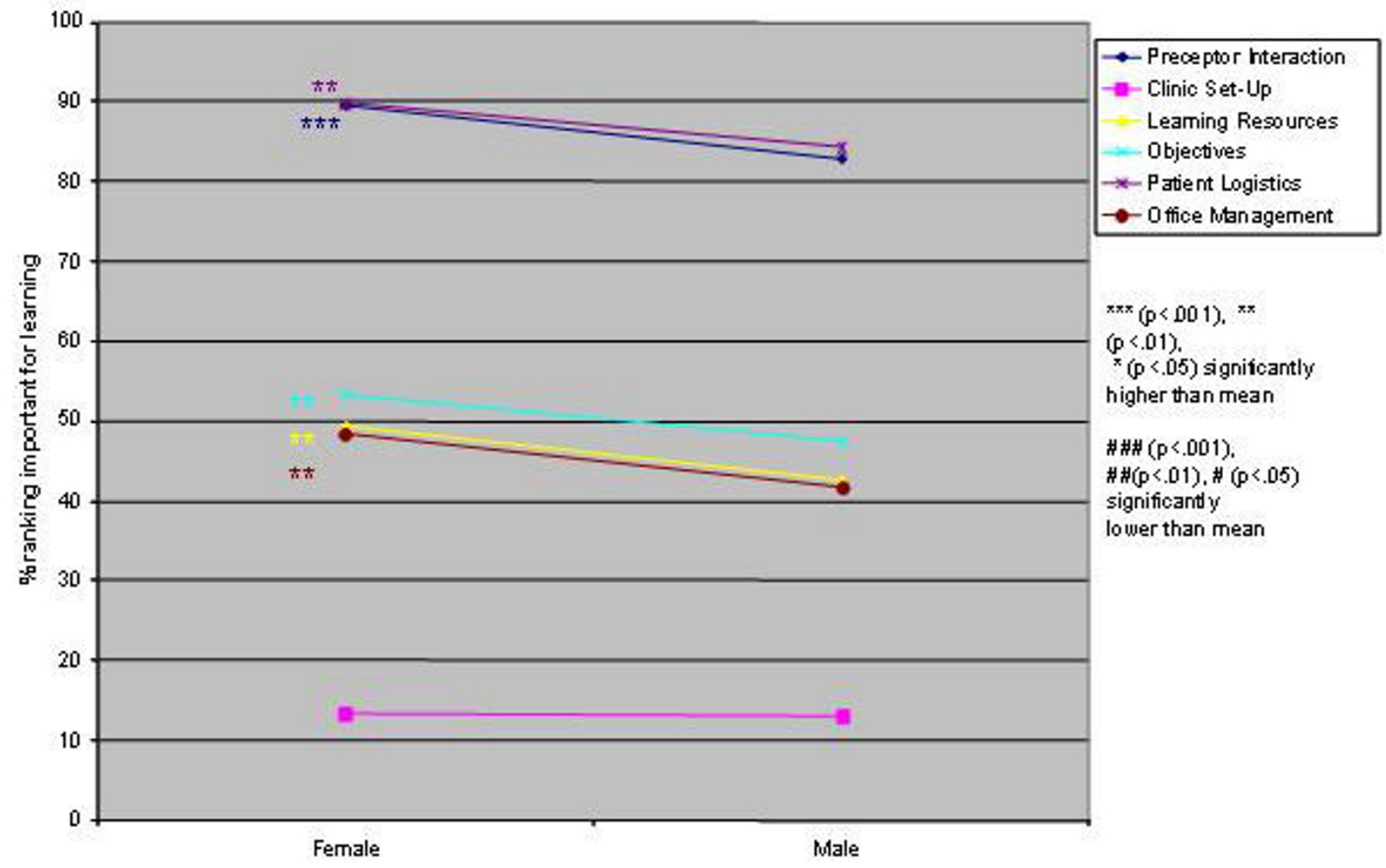

Figure I

Gender and site characteristics

been identified before and are well summarized by Bowen and Irby [19]. Little value is placed on having other trainees in the clinic despite social learning theory that suggests this enhances learning. Bowen [20] and Lesky [21] suggest that students learn by teaching and may feel less threatened asking questions that reveal a lack of knowledge of a fellow student than of a preceptor. Although what students value may not translate into effective learning, it is still important to understand why something is valued or not valued. Without reliable learning outcome measures perceived learning value is a proxy measure of learning effectiveness. Further studies should assess what learners do not like about having other trainees present.

Computer resources were more valued than books, likely reflecting a generation of learners who are comfortable accessing electronic information. Proximity of the clinic to university campus was unimportant. In contrast to other studies [22-24] we found block rotations were val- ued more than longitudinal rotations. Some programs, particularly Canadian Family Medicine programs, encourage longitudinal rotations to enhance the continuity of care experience. Merenstein et al [25] however recently reported there to be no difference in continuity of care provided by residents in longitudinal rotations. Exploration of the value of block versus longitudinal rotations is an area for further research.

Valued preceptor behaviours identified in this study are feedback by enthusiastic, open preceptors who are willing to discuss their reasoning processes and delegate responsibility. Recent studies report $3^{\text {rd }}$ year medical students to also value these preceptor behaviours[26,27]. Lesky and Borkan [21] suggest that pathogenesis and natural histories of disease can be learned from a variety of resources, including books and computers but problem solving, decision making and dealing with uncertainty are 


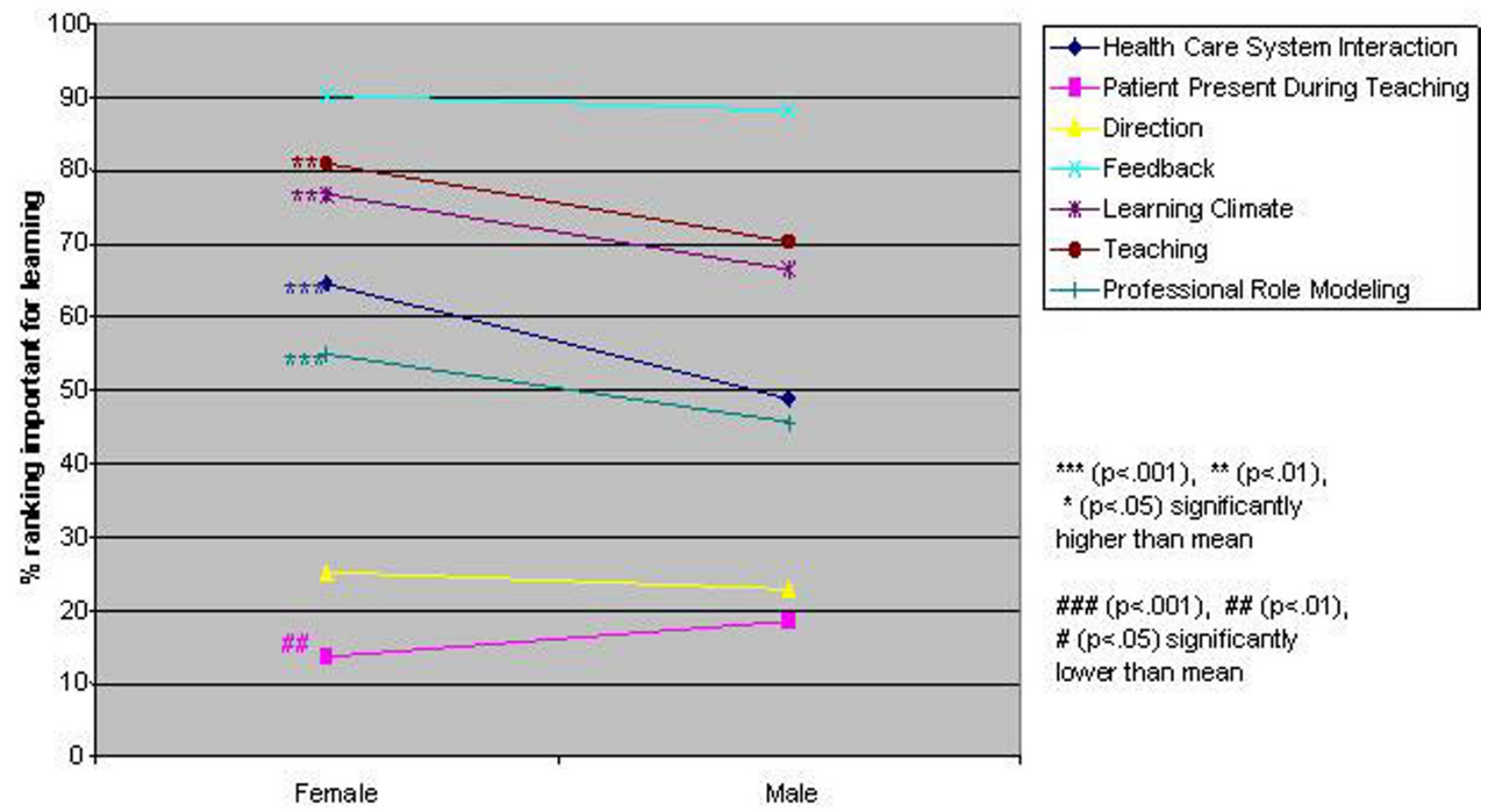

Figure 2

Gender and preceptor behaviours

learned mainly from preceptors and practice. This study supports students' perceived value of these aspects and suggests them as priorities for teachers in ambulatory settings.

We have confirmed the value of feedback found in most studies [26,28-31] (a study by O'Malley [32] being the exception). As one respondent commented "constructive and honest feedback in a timely manner is by far the most important (item)". Feedback leads to positive learning outcomes. Cope [33] demonstrated that giving feedback to residents improved their patient satisfaction scores, which in turn has been correlated with improved patient outcomes[34]. Unfortunately this teaching behaviour is underutilized. Irby [1], in a review of studies, reports that feedback is given only $3-6 \%$ of the time (range $0-16 \%$ ). This is an effective teaching behaviour that is valued by students and deserves high priority.

Meaningful feedback about many aspects of students' patient care is best based on direct observation[35]. Only
$61 \%$ of our respondents actually value direct observation by their preceptors. Some of the reasons for more not valuing this may be similar to why students do not want to be taught in front of the patient (see next section). Since direct observation is a necessary component of good teaching it will be important to explore further why more students do not value this important preceptor behaviour.

A number of strategies have been suggested to improve efficiency in the ambulatory teaching setting including teaching in the patient's presence and preceptors directing tasks to be covered in the interview [36-38]. A significant proportion of our respondents rated reviewing the case and teaching in the patient's presence, structuring the interview by providing patient information background, outlining tasks to be done during the interview and focusing on one teaching theme per clinic not only to be unimportant for learning but detrimental. Kernan similarly found $3^{\text {rd }}$ year medical students to not value being taught in front of the patient[26]. Comments from students in this study give some indication why teaching 


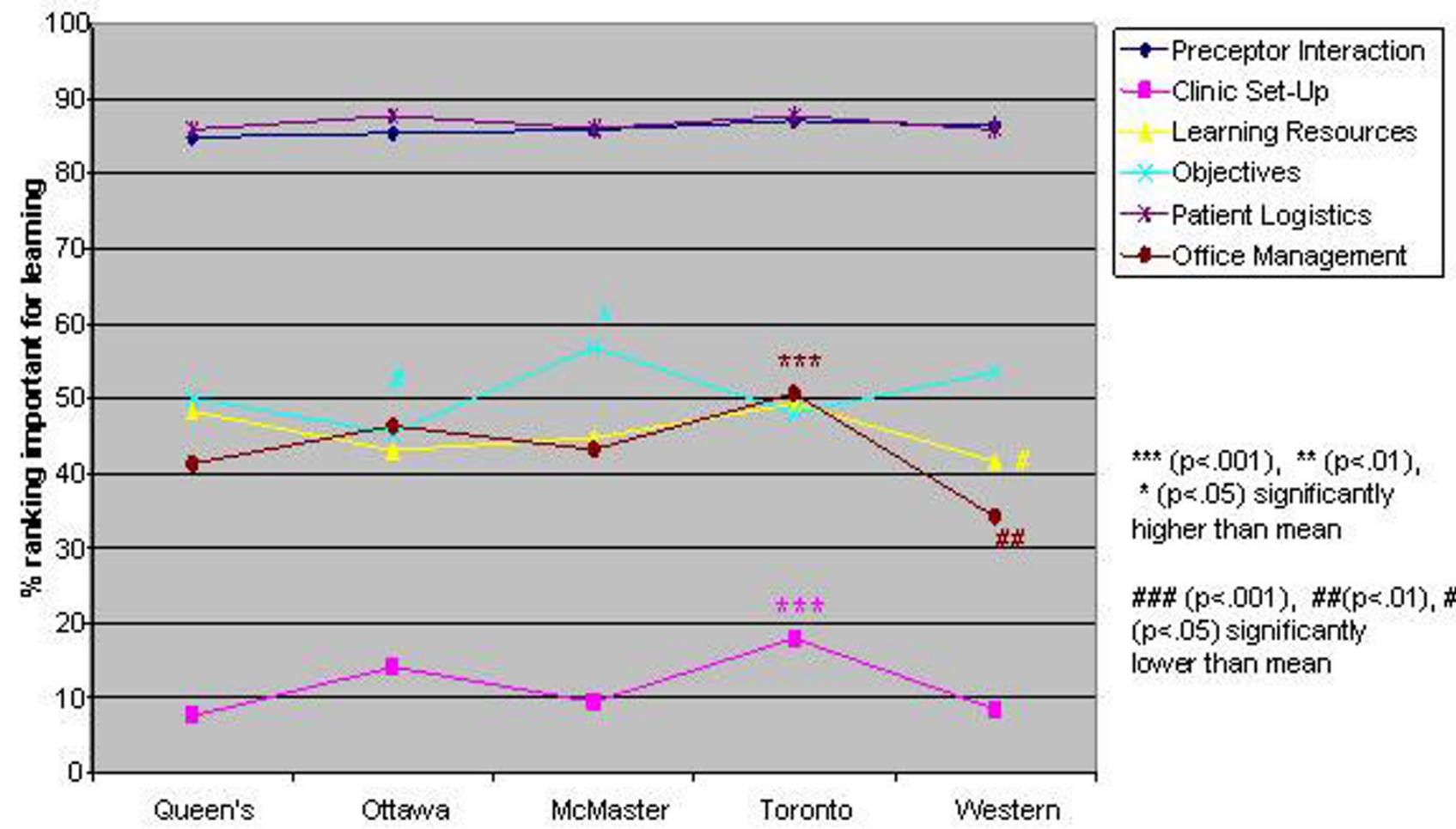

Figure 3

School and site characteristics

in front of the patient is disliked ("it would undermine a therapeutic alliance with the student", "it gives a tense atmosphere more often than not", "...impairs free thinking of student because student feels inhibition in front of patients", "makes it difficult for students to ask questions, not wanting to scare/worry the patient"). Teaching however occurs within a larger context where providing background information on patients may be necessary for ongoing patient care and safety and to model continuity of care. Teaching in the patient's presence may be necessary for efficiency and maintaining a relationship between the preceptor and the patient.Further studies are needed to determine if explanation or teaching methods can overcome this aversion.

Analysis of the impact of gender, school, level of training or residency on valued site characteristics and preceptor behaviours revealed striking uniformity between the groups. There were some statistically significant differences between the groups, many of which do not appear to be educationally relevant, others which likely are important.

Male and female students rank ordered site and preceptor behaviour factors identically. It is of interest that female students ranked all factors, with the exception of teaching in the patient's presence, as being more important for learning than male students. The literature [39-41] suggests that women predominantly emphasize relationship issues, which may partially explain this finding. It would appear however with respect to the items surveyed that there are no gender-based educationally important differences in valued site characteristics and preceptor behaviours.

The five schools also essentially rank ordered the factors identically. One school did stand out from the others in frequently ranking factors significantly higher than the rest. This school is the largest of the five schools with the most trainees and teaching sites. It would be valuable to 

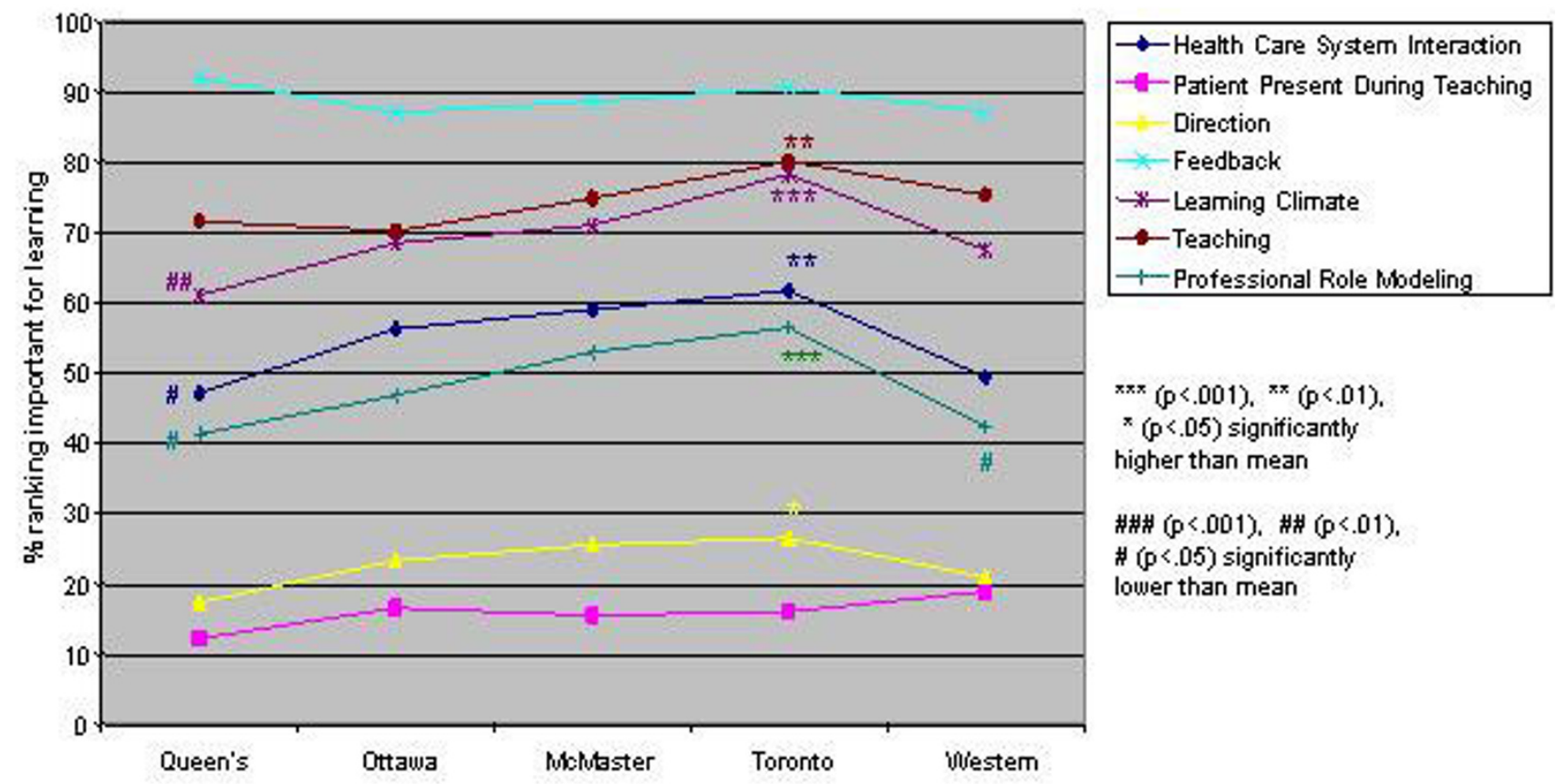

Figure 4

School and preceptor behaviours

know the ratio of students to preceptors at the different schools. If this were high at the larger school, perhaps resulting in residents feeling relatively anonymous, it may partially explain why these students there particularly value factors like learning climate, professional role modeling and clinic set up.

Within level of training preceptor interaction is most important for clerks. This is the only group to rank this item more important than patient logistics. This may reflect the clerks' developmental stage of being eager to go beyond textbook lists and start to put clinical decisions into patient context-skills best learned by preceptor interaction. Learning resources are significantly less valued by those at either end of their training-clerks for perhaps the above reason and PGY6's/fellows presumably because they are confident in their theoretical knowledge. Beyond clerkship patient logistic factors usurp preceptor interaction as the highest ranked site characteristic. Becoming an expert clinician involves, in part, connecting disparate units of knowledge into networks [3,5,42]. This encapsulating of knowledge occurs when students learn with patients. The residents in this study recognize this, ranking seeing an adequate and large variety of patients independently as the most important site characteristic for their learning. Having objectives defined with efforts made to meet them was third in importance for most levels, superceding available learning resources, office management skills instruction, and clinic setup items. Office management instruction is relatively more important for PGY2's and those at the end of their training. Subanalysis of the PGY2 data removing family medicine residents who would be at the end of their training and leaving those in the middle of their training significantly decreased the importance of office management and health care system interaction instruction. Teaching these aspects thus seems most important for those at the end of their training. Directing the clinical encounter and teaching in the patient's presence is valued less as residents gain seniority and presumably identify themselves more as the patients' physicians. Increasing desire for autonomy and decreasing potential for undermining their relationship with the patient may be reasons for these trends.

Within almost all residencies patient logistics and preceptor interaction are the most valued site characteristics; feedback, teaching and learning climate the most important preceptor behaviours. Lab/path, radiology and 

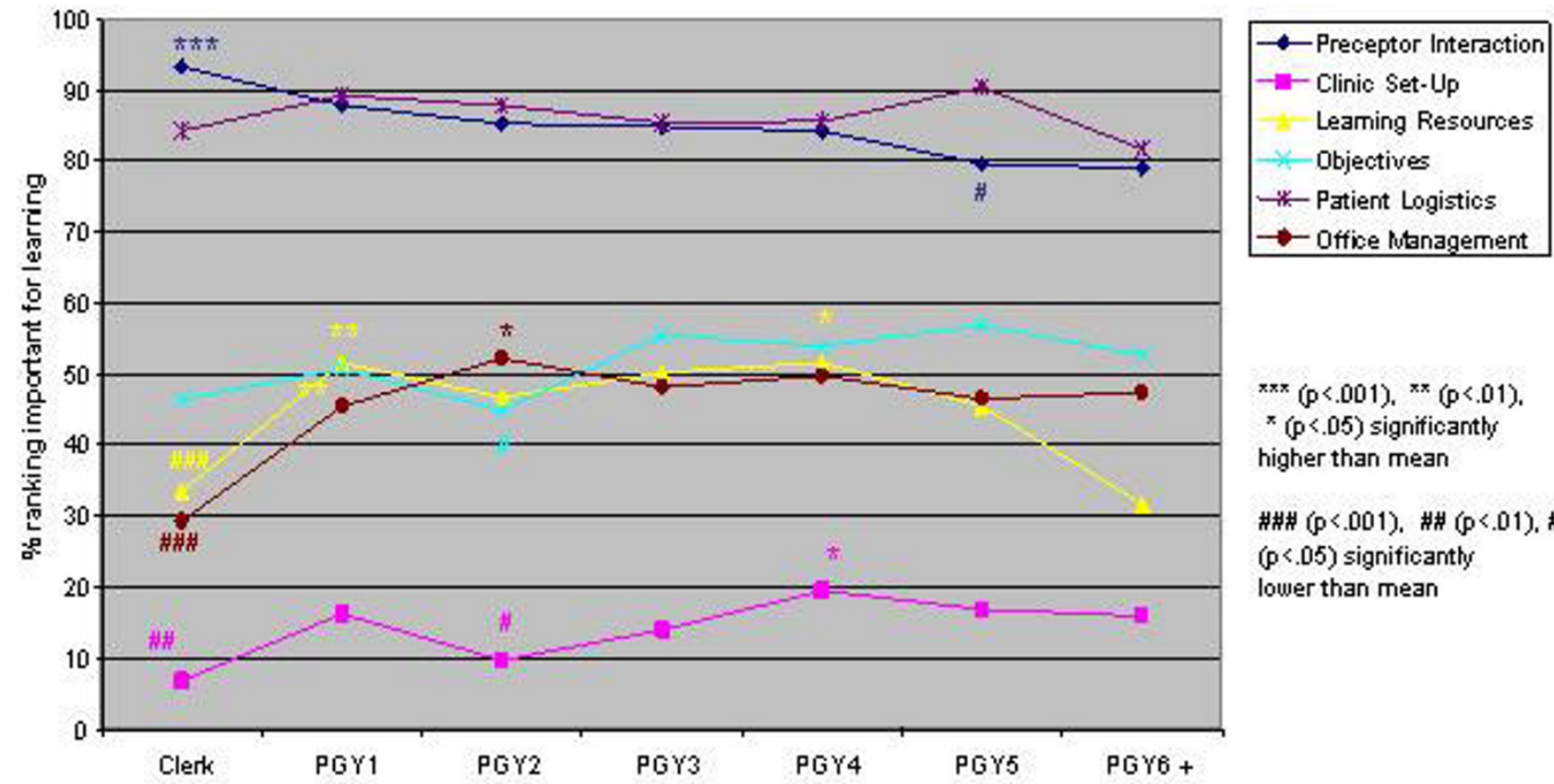

\#\#\# ( $<<.001)$ ， \#\# ( $<<.01)$ ， \# $(p<.05)$ significantly lower than mean

Figure 5

Training level and site characteristics

anaesthesia residents value all these preceptor behaviours less than other residents. Arguably these are areas of medicine where decision making is more clear-cut without as much patient input, which may explain these results. Other significant differences between the specialties seem best explained by considering future practice ie: officebased specialties (paediatrics, psychiatry, family medicine) most valuing office management and health care system interaction instruction.

Strengths of this study are the large multi-institutional sample size $(\mathrm{n}=1642)$ encompassing students at multiple levels in all specialties. The response rate (48\%) limits the external validity of the result. A confounding factor within the level of training data set may be the variability in residency lengths as suggested by the subanalysis of the PGY2 data. Rather than years from graduation from medical school what seems to influence valued site characteristics and preceptor behaviours more are years from independent practice.

\section{Conclusions}

"Software" (patient encounters and enthusiastic preceptors who delegate, give feedback and explain clinical reasoning) is valued more than "hardware" (clinic set-up, learning resources). All learners value the above preceptor behaviours; most do not value, and a significant number consider detrimental, having the structure of the patient encounter dictated to them and having the patient present during review and teaching. Future work is needed to explain why learners do not value these practices. Learners at all levels and in all specialties are strikingly similar in what they value from their preceptors and clinic sites for their learning. There are some differences between levels and residencies however that require consideration when teaching these different groups. Educationally significant differences within levels include preceptor interaction being paramount for medical students; patient logistics (adequate number and variety of patients seen independently and in follow-up) being second. The reverse is true for residents. Proportioning time accordingly deserves attention. The more senior the learner the more being taught or having the case reviewed in the patients' presence is not valued. Sensitivity to the patient-learner rela- 


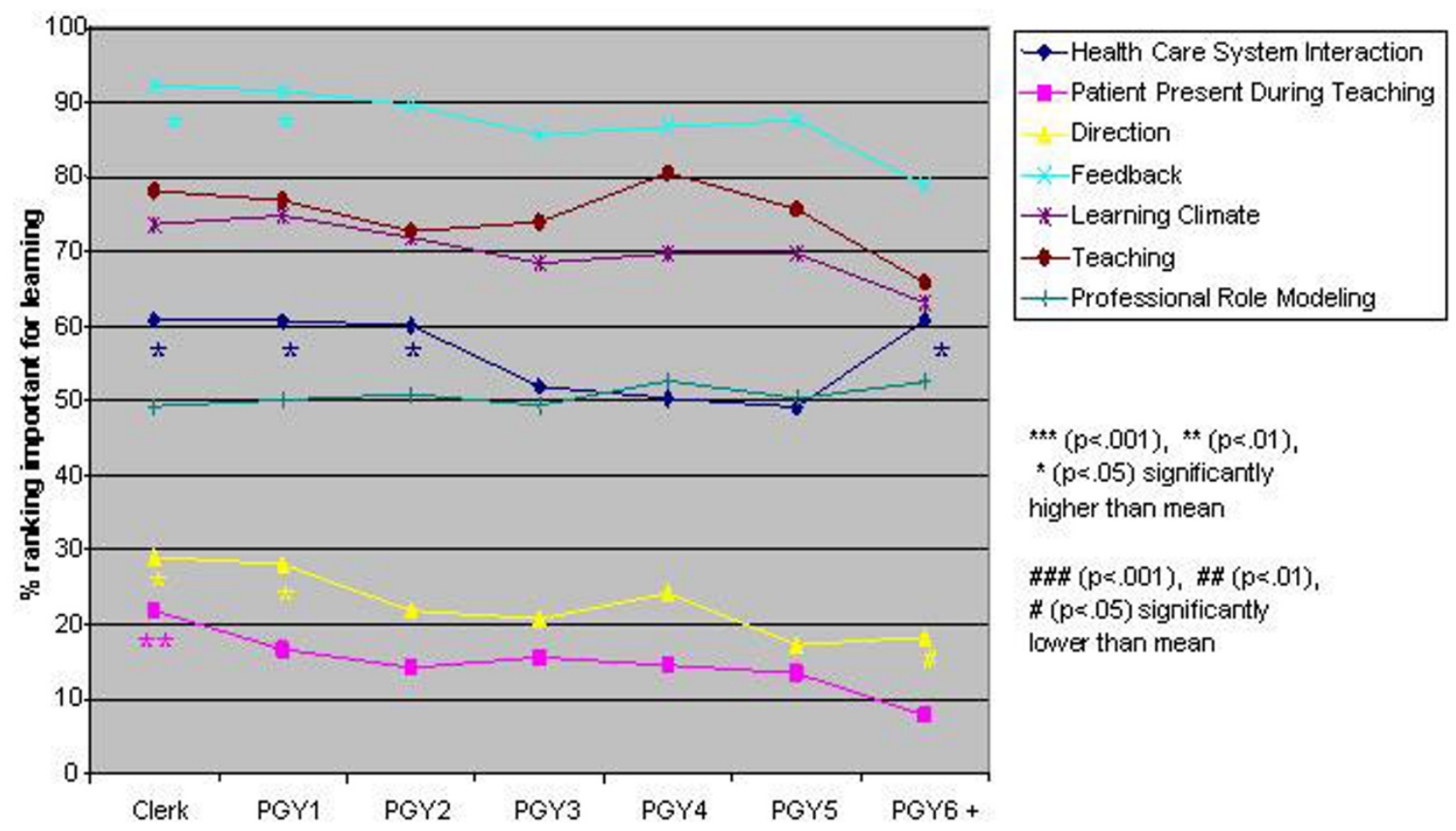

Figure 6

Training level and preceptor behaviours

tionship is required if these practices are utilized but particularly so for more senior learners. Finally relevance not surprisingly dictates importance. Office management instruction is valued by those at the end of their training and those primarily in office-based specialties. Similarly office-based specialties appreciate instruction in health care system interaction. This study identifies preceptor behaviours and site characteristics valued by medical students and residents for their learning in the ambulatory setting. Further studies are needed to determine the effect of providing these valued site characteristics and preceptor behaviours on learning outcomes.

\section{Competing interests}

None declared.

\section{Authors' contributions}

KS conceived of the study, prepared the manuscript and participated in the conceptual planning and design of the study and data interpretation. JK, DD, and MG participated in the conceptual planning and design of the study, statistical analysis and data interpretation and manuscript revision. SV and $\mathrm{RB}$ contributed to the design of the study and manuscript revision. CK contributed to the design of the study. All authors read and approved the final manuscript. RS participated in the statistical analysis. 

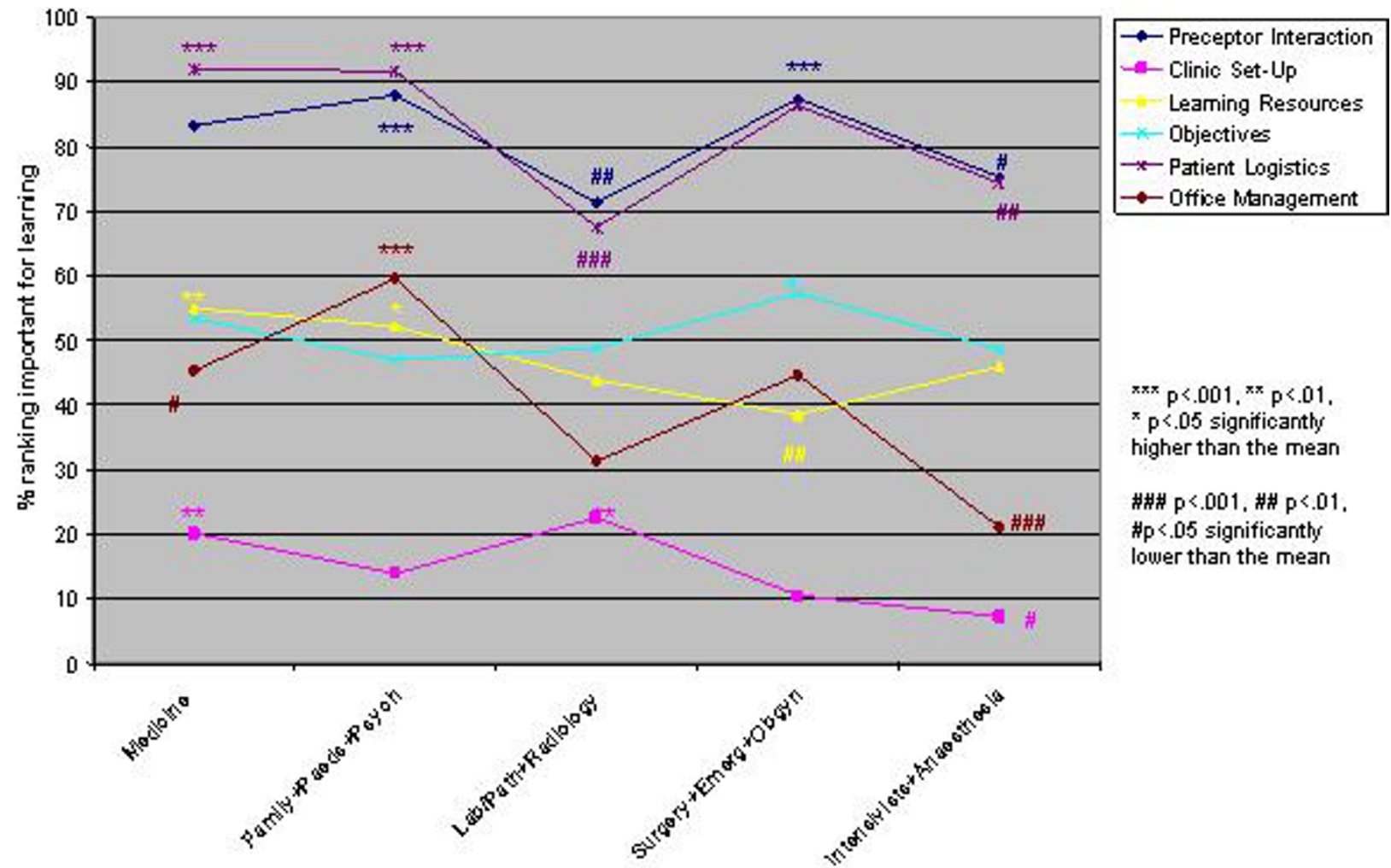

\#\#\# $\mathrm{p}<001$, \#\# $\mathrm{p}<0.01$. $\# p<.05$ significantly lower than the mean

Figure 7

Residency and site characteristics

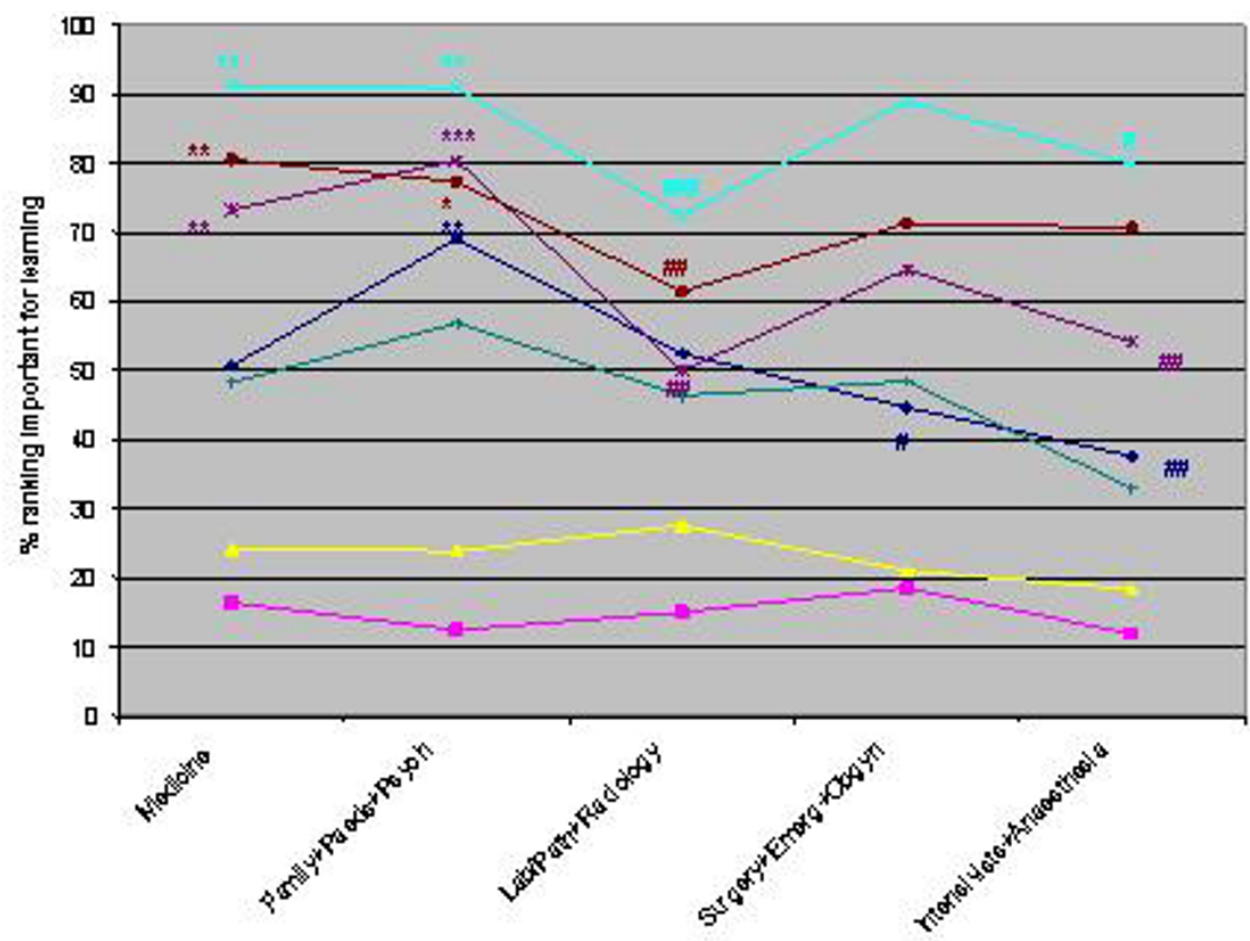

\begin{tabular}{|c|}
\hline 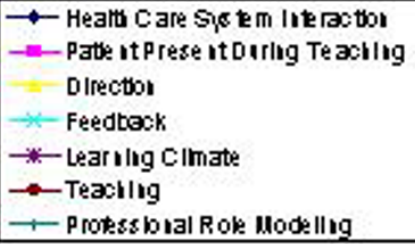 \\
\hline
\end{tabular}

" $p=001, " \mu p=D 1$, - $p=05$ sigumear br ingerthat the meas

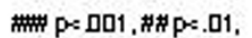

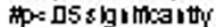
bwertia the meas

Figure 8

Residency and preceptor behaviours 


\section{Acknowledgements}

I am grateful to CIHR-ACMC for funding this project. I would like to thank Jason Schmelzle for his diligent data entry and Debbie Jones for assisting with finalizing the manuscript.

\section{References}

I. Irby DM: Teaching and learning in ambulatory care settings. A thematic review of the literature. Academic Medicine 1995 70(10):898-93I.

2. Lesky LG, Hershman WY: Practical approaches to a major educational challenge. Arch Intern Med 1995, I 55:897-904.

3. Van de Wiel MWJ, Boshuizen HPA: The explanation of clinical concepts by expert physicians, clerks, and advanced students. Teaching and Learning in Medicine 1999, I I(3): I53-I63.

4. Perry WG Jr: Intellectual and ethical development. Troy, Mo: Holt Rinehart and Winston 1972.

5. Shatzer JH: Instructional methods. Academic Medicine I998, 73(9):S38-S45.

6. Kosower E, Berman N: Comparison of pediatric resident and faculty learning styles: Implications for medical education. Am J Med Sci 1996, 3 I 2(5):214-218.

7. Stritter FT, Baker RM: Resident preferences for the clinical teaching of ambulatory care. J Med Educ 1982, 57:33-4I.

8. Sadler GR, Plovnick M, Snope FC: Learning styles and teaching implications. I Med Educ 1978, 53:847-849.

9. Kolb DA: Experiential learning. Experience as the source of learning and development. Englewood Cliffs, NJ:. Prentice Hall PTR 1984:6I-98.

10. Plovnick MS: Primary Care career choices and medical student learning styles. J Med Educ 1975, 50:849-855.

I I. Baker JD, Reines HD, Wallace CT: Learning style analysis in surgical training. The American Surgeon 1985, 5 I:494-496.

12. Kernan WN, O'Connor PG: Site accommodations and preceptor behaviors valued by $3^{\text {rd }}$ year students in ambulatory internal medicine clerkships. Teaching and Learning in Medicine 1997, 9:96-102.

13. Goertzen J, Stewart M, Weston W: Effective teaching behaviours of rural family medicine preceptors. CMAJ I995, | 53(2): $161-168$

14. Heindenreich C, Lye P, Simpson D, Lourich M: Educating child health professionals: The search for effective and efficient ambulatory teaching methods through the literature. Pediatrics 2000, 105:231-237.

15. Lawrence SL, Lindemann JC, Gottlieb M: What students value: Learning outcomes in a required third-year ambulatory primary care clerkship. Academic Medicine 1999, 74(6):7I5-7I7.

16. Kirby JR, Knapper CK, Evans CJ, Carty AE, Gadula C: Approaches to learning at work and workplace climate. International J.of Training and Development 2003, 7:31-52.

17. SPSS Inc: Statistical package for the social sciences. SPSS Base I I.0 SPSS Inc, Chicago, IL 2003.

18. Tabachnick BG, Fidell LS: Using multivariate statistics. Boston. Allyn and Bacon 4200I.

19. Bowen JL, Irby DM: Assessing quality and costs of education in the ambulatory setting: A review of the literature. Academic Medicine 2002, 77(7):62I-680.

20. Bowen JL, Stearns JA, Dohner C, Blackman J, Simpson D: Defining and evaluating quality for ambulatory care educational programs. Academic Medicine 1997, 72(6):506-5I0.

21. Lesky LG, Borkan SC: Strategies to improve teaching in the ambulatory medicine setting. Arch Intern Med 1990, I 50:2133-2137.

22. Glasser M, Gravdal J: Graduates' assessment of undergraduate training in ambulatory primary care education. J Med Educ 1987, 62:385-393.

23. Lofgren RP, Mladenovic J: How reorganizing a general medicine clinic affected residents' and patients' satisfaction. Academic Medicine 1990, 65:604-608.

24. Prislin MD, Feighney KM, Stearns JA, Hood J, Arnold L, Erney S, Johnson $L$ : What students say about learning and teaching in longitudinal ambulatory primary care clerkships: A multiinstitutional study. Academic Medicine 1998, 73(6):680-687.

25. Merenstein D, D'Amico F, Devine B, Mahaniah KJ, Solomon M, Reust $\mathrm{CE}$, Rosenbaum DJ: Longitudinal versus traditional residencies:
A study of continuity of care. Family Medicine 200I, 33(10):746-750.

26. Kernan WN, Lee MY, Stone SL, Freudigman KA, O'Connor PG: Effective teaching for preceptors of ambulatory care: $A$ survey of medical students. Am J Med 2000, I 08:499-502.

27. Elnicki DM, Kolarik R, Bardella I: Third-year medical students' perception of effective teaching behaviors in a multidisciplinary ambulatory clerkship. Academic Medicine 2003, 78(8):815-819.

28. Wright SM, Kern DE, Kolodner K, Howard DM, Brancati FL: Attributes of excellent attending physician role models. NEJM 1998, 339:1986-1993.

29. Gil DH, Heins M, Jones PB: Perceptions of medical school faculty members and students on clinical clerkship feedback. Med Educ 1984, 59:856-864.

30. Medio FJ, Wilkerson L, Reinhard JD, Maxwell JA, Cohen RM: Improving teaching rounds: Action research in medical education. Proc Res Med Educ 1984, 23:283-288.

31. Kroenke K, Simmons JO, Copley JB, Smith C: Attending rounds: A survey of physician attitudes. J Gen Intern Med I990, 5:229-233.

32. O'Malley PG, Kroenke K, Ritter J, Dy N, Pangaro L: What learners and teachers value most in ambulatory educational encounters: A prospective, qualitative study. Academic Medicine 1999 , 74(2): $|86-19|$.

33. Cope DW, Linn LS, Leake BD, Barrett PA: Modification of resident's behavior by preceptor feedback of patient satisfaction. J Gen Intern Med 1986, I:394-398.

34. Stewart MA: Effective physician-patient communication and health outcomes: A review. CMAJ 1995, I 52(9): |423-|433.

35. Holmboe ES: Faculty and the observation of trainees' clinical skills: Problems and opportunities. Academic Medicine 2004, 79(I): I6-22.

36. Ferenchick G, Simpson D, Blackman J, DaRosa D, Dunnington G: Strategies for efficient and effective teaching in the ambulatory care setting. Academic Medicine 1997, 72(4):277-280.

37. Regan-Smith M, Young WW, Keller AM: An efficient and effective teaching model for ambulatory education. Academic Medicine 2002, 77:593-599.

38. Usatine RP, Nguyen K, Randall J, Irby DM: Four exemplary preceptors' strategies for efficient teaching in managed care settings. Academic Medicine 1997, 72:766-769.

39. Lieberman PB, Sledge WH, Matthews DA: Effect of Patient Gender on Evaluation of Intern Performance. Arch Intern Med 1989, 149: |825-1829.

40. Gilligan C: In a different voice: Women's conception of self and morality. Harvard Edu Review 1988, 47:48I-5I7.

41. Gilligan C: New maps of development, new visions of maturity. Am J Orthopsychiatry 1982, 52:199-212.

42. Regehr G, Norman GR: Issues in cognitive psychology: Implications for professional education. Academic Medicine 1996, 71:988-1001.

\section{Pre-publication history}

The pre-publication history for this paper can be accessed here:

http://www.biomedcentral.com/1472-6920/4/12/prepub 